\title{
Extremely low flow tracheal gas insufflation of helium-oxygen mixture improves gas exchange in a rabbit model of piston-type high-frequency oscillatory ventilation
}

\author{
Atsushi Baba ${ }^{1 \dagger}$, Tomohiko Nakamura ${ }^{2 *}$, Tetsuya Aikawa ${ }^{3 \dagger}$ and Kenichi Koike ${ }^{1+}$
}

* Correspondence:

tnakamura@naganoch.gr.jp

${ }^{\dagger}$ Equal contributors

2Division of Neonatology, Nagano

Children's Hospital, Toyoshina,

Azumino City, Nagano 399-8288,

Japan

Full list of author information is

available at the end of the article

\section{Abstract \\ Objective: The purpose of this study was to show the effects of the tracheal gas insufflation (TGl) technique on gas exchange using helium-oxygen mixtures during high-frequency oscillatory ventilation (HFOV). We hypothesized that a helium-oxygen mixture delivered into the trachea using the TGl technique $(0.3 \mathrm{~L} / \mathrm{min})$ would enhance gas exchange during HFOV.}

Methods: Three rabbits were prepared and ventilated by HFOV with carrier $70 \%$ helium/oxygen or 70\% nitrogen/oxygen gas mixture with TGI in a crossover study. Changing the gas mixture from nitrogen $70 \%$ to helium $70 \%$ and back was performed three times per animal with constant ventilation parameters.

Results: Compared with the nitrogen-oxygen mixture, the helium-oxygen mixture of TGl reduced $\mathrm{PaCO}_{2}$ by $7.6 \mathrm{mmHg}(p<0.01)$ and improved $\mathrm{PaO}_{2}$ by $14 \mathrm{mmHg}$ $(p<0.01)$. Amplitude during TGI was significantly lower with the helium-oxygen mixture than with the nitrogen-oxygen mixture $(p<0.01)$ and did not significantly affect mean airway pressure.

Conclusions: This study demonstrated that a helium-oxygen mixture delivered into the trachea using the TGI technique would enhance $\mathrm{CO}_{2}$ elimination and improve oxygenation during HFOV.

\section{Background}

In spite of advances in approach and therapeutic benefits of conventional mechanical ventilation in respiratory failure in the neonatal intensive care unit (NICU), ventilatorinduced lung injury remains a major problem. This is particularly relevant in patients who need aggressive maintenance of pressures and $\mathrm{FiO}_{2}$ for adequate oxygenation. In such patients, high-frequency oscillatory ventilation (HFOV) has been considered advantageous for maintaining oxygenation using higher mean airway pressure with minimal risk of complication. During HFOV, tidal volume (Vt) and associated swings in alveolar pressure are very small [1,2]. HFOV has been used in a variety of clinical situations, including neonatal respiratory distress syndrome (RDS), congenital diaphragmatic hernia (CHD), meconial aspiration syndrome (MAS), air leak syndrome and other [3-5]. HFOV showed a number of different mechanisms in addition to bulk convection that have been 
postulated to account for gas exchange, including Taylor dispersion and turbulence, asymmetric velocity profiles, pendelluft, cardiogenic mixing, collateral ventilation and molecular diffusion [6].

Helium is a noble gas, with very low atomic weight $(4 \mathrm{~g} / \mathrm{mol})$ and density $(0.157 \mathrm{~g} / \mathrm{L}$ at $37^{\circ} \mathrm{C}$ and $\left.1 \mathrm{~atm}\right)$. The density of helium-oxygen mixture reduces the resistance factor in gas delivery [7]. This increased mobility has three effects: gas more readily reaches the alveoli, thus allowing greater diffusion; breathing effort is significantly reduced by using a less-dense gas; and carbon dioxide is eliminated more rapidly through a helium-oxygen mixture than through a nitrogen-oxygen mixture [8-10]. In HFOV with helium, both properties may contribute to improved ventilation [11]. Winters et al. reported a case series of children with respiratory acidosis during HFOV. When the carrier gas was changed to a helium-oxygen mixture, $\mathrm{CO}_{2}$ clearance improved [12]. Helium-oxygen mixtures have been examined using HFOV in animal models $[9,10,13]$. Those experiments showed that the improvement of ventilation with a helium-oxygen mixture was related to a larger Vt delivery by the oscillator under the same amplitude (AMP). If Vt during HFOV is maintained at a constant level, use of a helium-oxygen mixture does not alter gas exchange in HFOV ventilators with either a membrane-driven oscillator [10] or a piston-driven oscillator [13].

Continuous tracheal gas insufflation (TGI) is a technique that flushes dead space, and may thus allow reductions in respiratory support. Kakous et al. [14] reported the effects of continuous TGI in conventional ventilation. The effect of TGI is based mainly on the replacement of end-tidal gas in the instrumental dead space with an inspiratory gas mixture.

We hypothesized that a helium-oxygen mixture delivered into the trachea using a TGI technique $(0.3 \mathrm{~L} / \mathrm{min})$ would enhance $\mathrm{CO}_{2}$ elimination during HFOV. The purpose of this study was to compare the effects of TGI on gas exchange using helium-oxygen and nitrogen-oxygen mixtures in a rabbit model during HFOV.

\section{Methods}

\section{Bench test}

To elucidate the physical effects of reducing gas density during HFOV with TGI, we performed a bench test utilizing a test lung. A schematic of the experimental system is shown in Figure 1. The test lung (NeoLung; IngMar Medical, PA) was connected to the endotracheal tube (ETT) with a monitoring lumen (internal diameter, $3.5 \mathrm{~mm}$; Mallinckrodt, St. Louis, MO), and attached to the circuit of a piston-driven highfrequency ventilator (Humming II; Metran, Saitama, Japan). Static compliance and resistance of the test lung were $1.3 \mathrm{~mL} / \mathrm{cmH}_{2} \mathrm{O} / \mathrm{kg}$ and $160 \mathrm{cmH}_{2} \mathrm{O} / \mathrm{L} / \mathrm{s} / \mathrm{kg}$, respectively. Pressure at the Y-piece of the circuit was monitored using a pressure sensor (AP-C35; Keyence, Osaka, Japan). The carrier gas (nitrogen-oxygen or helium-oxygen mixture, 78:22 mixture ratio; bias flow rate, $8 \mathrm{~L} / \mathrm{min}$ ) inside the HFOV circuit was oscillated using the piston-driven Humming II with mean airway pressure set at $12 \mathrm{cmH}_{2} \mathrm{O}$, stroke volume (SV) at $15 \mathrm{~mL}$, and frequency at $15 \mathrm{~Hz}$.

In the series of HFOV with TGI, the carrier gas inside the HFOV circuit was a nitrogen-oxygen mixture (78:22 mixture ratio). Insufflating gas flow (nitrogen-oxygen mixture, 78:22 mixture ratio; or helium-oxygen mixture, 78:22 mixture ratio) through 


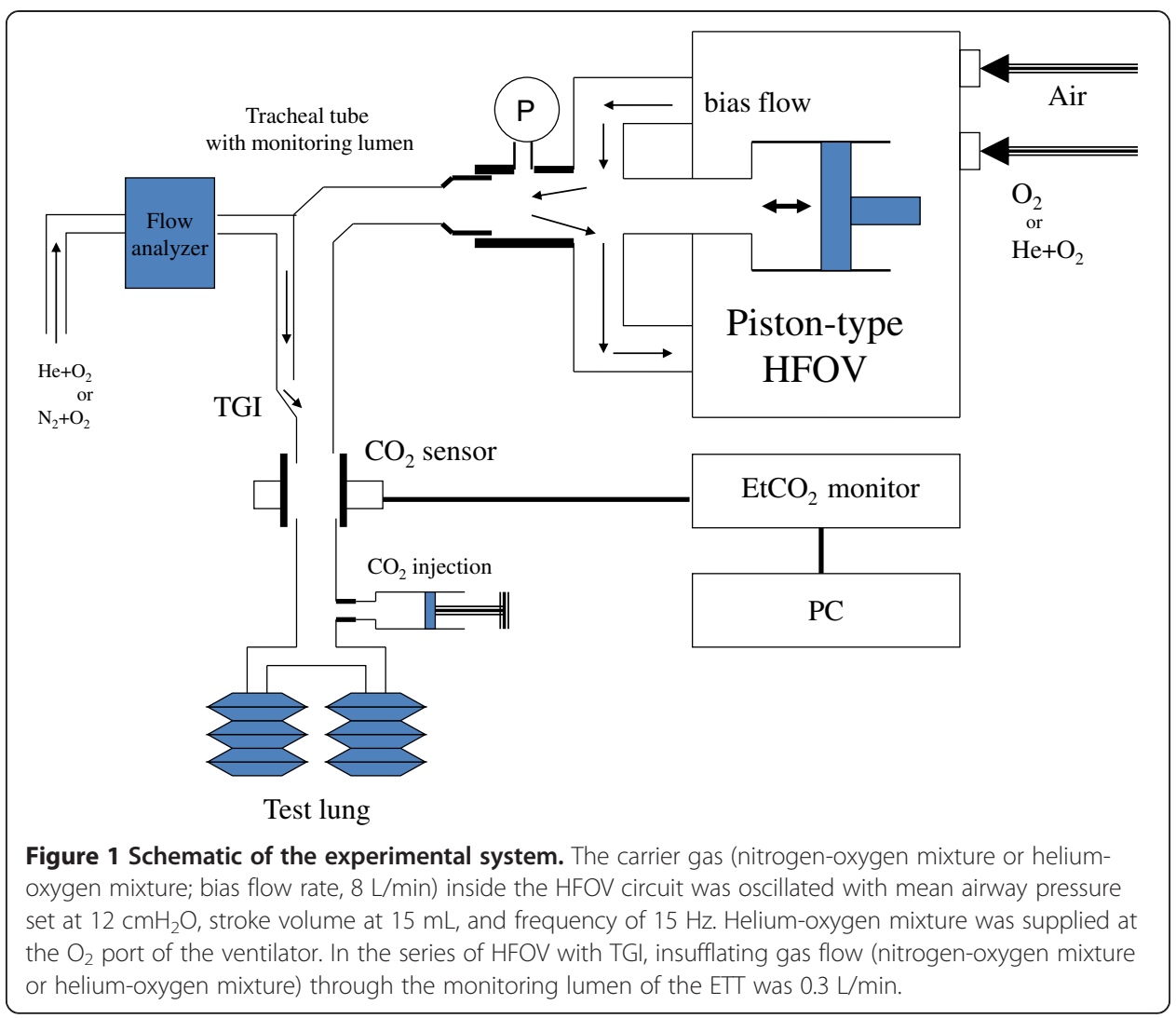

the monitoring lumen of the ETT was $0.3 \mathrm{~L} / \mathrm{min}$. We used a helium-calibrated flow analyzer (PF-300; ImtMedical, Buchs, Switzerland) to ensure that TGI flow of the two gases was equal. To compare the speed of $\mathrm{CO}_{2}$ transport, $5 \mathrm{ml}$ of tracer gas $\left(\mathrm{CO}_{2}\right)$ was injected into the system through an access port near the test lung. $\mathrm{CO}_{2}$ partial pressure at the end of the ETT was monitored using an $\mathrm{EtCO}_{2}$ monitor (OLG-2800; Nihon Kohden, Tokyo, Japan). Real-time data from the $\mathrm{EtCO}_{2}$ monitor were collected using a computerized data accumulation system at a sampling rate of 200 samples/s. The single exponential curve describing the $\mathrm{CO}_{2}$ concentration inside the system for $3 \mathrm{~s}$ was approximated by nonlinear regression (Excel 2010; Microsoft, WA). We used the equation: measured $\mathrm{CO}_{2}$ concentration $=a \exp ^{-b}$, where $a$ and $b$ are the variables obtained by curve fitting and $t$ is the time of $\mathrm{CO}_{2}$ measurement from the point at which $\mathrm{CO}_{2}$ concentration was $100 \mathrm{mmHg}$, representing the upper limit of the measurement capability of the $\mathrm{EtCO}_{2}$ monitor. All experiments were repeated six times.

\section{Animal preparation}

All study protocols were approved by the Institutional Animal Care and Use Committee of Shinshu University, Nagano, Japan. Three Japanese white rabbits (body weight, $2.309 \pm 0.131 \mathrm{~kg}$ ) were used in the study. Animals were premedicated by intramuscular administration of midazolam (10 mg/ $/ \mathrm{kg} /$ dose) and xylazine $(5 \mathrm{mg} / \mathrm{kg} / \mathrm{dose})$. The ear vein was cannulated using a 24-G angiocatheter for intravenous anesthesia and hydration. Animals were placed in a supine position under a radiant warmer to maintain body temperature throughout the entire study period, and body temperature was 
Tmonitored using a rectal temperature probe. Tracheotomy was performed, and a no-cuff ETT with monitoring lumen (internal diameter, $3.5 \mathrm{~mm}$; Mallinckrodt), was inserted to a depth of $3 \mathrm{~cm}$ from the lower edge of the cricoid cartilage and fixed in place. Intermittent ventilation (IMV) was initiated using a time-cycled, pressure-limited ventilator (Humming II; Metran). Using a digital pressure sensor (AP-C40; Keyence) installed into the Y-piece of the breathing circuit, actual pressure parameters were measured and registered.

Static compliance and resistance were measured by the passive expiratory flowvolume method, using a pneumotachograph (LFM-317 Aivision Laminar Flow Meter, Metabo, Lausanne, Switzerland). During this procedure, we confirmed that no leakage was present. Anesthesia and myoparalysis were provided by continuous intravenous infusion of midazolam $(0.1 \mathrm{mg} / \mathrm{kg} / \mathrm{h})$, xylazine $(3 \mathrm{mg} / \mathrm{kg} / \mathrm{h})$ and pancuronium $(0.1 \mathrm{mg} / \mathrm{kg} / \mathrm{h})$. The carotid artery was then cannulated for direct blood pressure measurement, heart rate (HR) monitoring and determination of arterial blood gases (ABG).

\section{Interventions and measurements}

Animals were allowed 20 min for stabilization under IMV. After sustained inflation maneuver at $20 \mathrm{cmH}_{2} \mathrm{O}$ for $10 \mathrm{~s}$, ventilation mode was shifted to the HFOV mode of the same ventilator (Humming II; Metran). ABG was obtained after $10 \mathrm{~min}$ of ventilation with: mean airway pressure (MAP), $12 \mathrm{cmH}_{2} \mathrm{O}$; frequency, $15 \mathrm{~Hz} ; \mathrm{FiO}_{2}, 0.30$; and bias flow rate, $8 \mathrm{~L} / \mathrm{min}$. SV (same as Vt) was adjusted to $4.16 \pm 0.57 \mathrm{ml}$ (mean \pm standard deviation) to obtain permissive hypercapnia. The target $\mathrm{PaCO}_{2}$ was $70 \mathrm{mmHg}$. Amplitude (AMP) was a subordinate factor during HFOV with the piston-driven oscillator, which was influenced by SV, animal airway condition (especially compliance) and the nature of the gas in the circuit. After baseline recordings were taken, tracheal gas was insufflated through the second monitoring lumen of the ETT for $10 \mathrm{~min}$ at gas flow of $0.3 \mathrm{~L} / \mathrm{min}$. In our preliminary experiment in healthy rabbits, steady state was reached after approximately 5 min during HFOV with TGI. After data collection with a nitrogen-oxygen mixture (70:30 mixture ratio), the gas for TGI was switched to a helium-oxygen mixture (70:30 mixture ratio, $0.487 \mathrm{~g} / \mathrm{L}$ at $37^{\circ} \mathrm{C}$ and $\left.1 \mathrm{~atm}\right)$ and

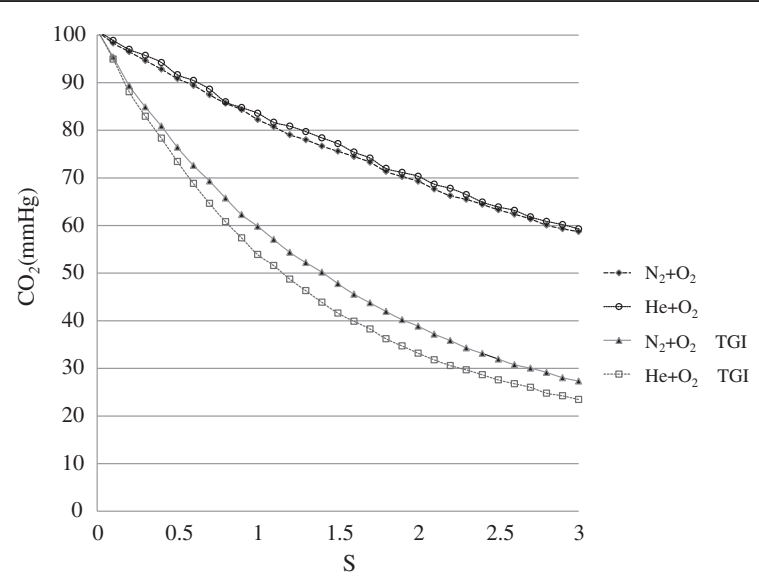

Figure $2 \mathrm{CO}_{2}$ elimination curve. The average of $\mathrm{CO}_{2}$ elimination in comparison of nitrogen-oxygen and helium-oxygen mixtures with or without TGl. 
Table 1 Effects of the speed of $\mathrm{CO} 2$ transport on the time constant

\begin{tabular}{|c|c|c|c|}
\hline Insufflating gas & Non-linear regression & b & Time constant $=1 /|b|$ \\
\hline \multirow[t]{7}{*}{ Helium-oxygen } & $y=91.641 e^{-0.4848 x}$ & -0.4848 & 2.06 \\
\hline & $y=91.24 e^{-0.4986 x}$ & -0.4986 & 2.01 \\
\hline & $y=89.045 e^{-0.4748 x}$ & -0.4748 & 2.11 \\
\hline & $y=91.327 e^{-0.4936 x}$ & -0.4936 & 2.03 \\
\hline & $y=93.579 e^{-0.4859 x}$ & -0.4859 & 2.06 \\
\hline & $y=92.799 e^{-0.492 x}$ & -0.492 & 2.03 \\
\hline & & & mean \pm SD $2.05 \pm 0.04$ \\
\hline \multirow[t]{7}{*}{ Nitrogen-oxygen } & $y=94.984 e^{-0.436 x}$ & -0.436 & 2.29 \\
\hline & $y=94.806 e^{-0.436 x}$ & -0.436 & 2.29 \\
\hline & $y=94.334 e^{-0.436 x}$ & -0.436 & 2.29 \\
\hline & $y=95.175 e^{-0.4367 x}$ & -0.4367 & 2.29 \\
\hline & $y=93.381 e^{-0.4321 x}$ & -0.4321 & 2.31 \\
\hline & $y=96.175 e^{-0.437 x}$ & -0.437 & 2.29 \\
\hline & & & mean \pm SD $2.3 \pm 0.01$ \\
\hline Bias flow gas & Non-linear regression & b & Time constant $=1 /|b|$ \\
\hline \multirow[t]{7}{*}{ Helium-oxygen } & $y=101.18 e^{-0.182 x}$ & -0.182 & 5.49 \\
\hline & $y=100.9 e^{-0.181 x}$ & -0.181 & 5.52 \\
\hline & $y=99.006 e^{-0.1774 x}$ & -0.1774 & 5.64 \\
\hline & $y=100.35 e^{-0.1807 x}$ & -0.1807 & 5.53 \\
\hline & $y=101.64 e^{-0.1797 x}$ & -0.1797 & 5.56 \\
\hline & $y=99.601 e^{-0.1771 x}$ & -0.1771 & 5.65 \\
\hline & & & mean \pm SD $5.57 \pm 0.06$ \\
\hline \multirow[t]{7}{*}{ Nitrogen-oxygen } & $y=99.37 e^{-0.1925 x}$ & -0.1925 & 5.19 \\
\hline & $y=98.925 e^{-0.1801 x}$ & -0.1801 & 5.55 \\
\hline & $y=100.75 e^{-0.1751 x}$ & -0.1751 & 5.71 \\
\hline & $y=99.517 e^{-0.1738 x}$ & -0.1738 & 5.75 \\
\hline & $y=100.72 e^{-0.1733 x}$ & -0.1733 & 5.77 \\
\hline & $y=96.836 e^{-0.1912 x}$ & -0.1912 & 5.23 \\
\hline & & & mean \pm SD $5.54 \pm 0.26$ \\
\hline
\end{tabular}

ventilated for $10 \mathrm{~min}$ before obtaining data. After data collection with the heliumoxygen mixture (70:30), the gas for TGI was returned to the nitrogen-oxygen mixture (70:30), and allowed $10 \mathrm{~min}$ to stabilize before data collection. HFOV settings were held constant while the gas mixture of TGI was changed. The cycle of changing the gas mixture from nitrogen-oxygen mixture to helium-oxygen mixture and back was performed three times per animal. To ensure that animal conditions returned to baseline after each experiment, rabbits were ventilated under HFOV without TGA.

\section{Statistics}

Data were analyzed by Wilcoxon $t$-test, one-way analysis of variance (ANOVA) or repeated-measures ANOVA, followed by the Bonferroni test to compare matched experimental sets. All data are presented as mean \pm standard error of the mean. Significance was defined for values of $\mathrm{p}<0.01$. 


\section{Results}

\section{Bench test}

The $\mathrm{CO}_{2}$ elimination curve is shown in Figure 2. Speed of $\mathrm{CO}_{2}$ transport is expressed as the time for the $\mathrm{CO}_{2}$ concentration to reach $63 \%$ of the final concentration (time constant). Effects of the speed of $\mathrm{CO}_{2}$ transport on the time constant are summarized in Table 1. When the carrier gas inside the HFOV circuit was changed without TGI, the time constant was $5.54 \pm 0.26 \mathrm{~s}$ with the nitrogen-oxygen mixture and $5.57 \pm 0.06 \mathrm{~s}$ with the helium-oxygen mixture. When the gas for TGI was changed to a low-density gas, speed of $\mathrm{CO}_{2}$ transport increased, as reflected by a significant fall in time constant from $2.3 \pm 0.01 \mathrm{~s}$ with the nitrogen-oxygen mixture to $2.05 \pm 0.04 \mathrm{~s}$ with the heliumoxygen mixture $(\mathrm{p}<0.01)$.

\section{Animal experiments}

We compared $\mathrm{PaCO}_{2}$ and $\mathrm{PaO}_{2}$ values obtained after 10 min of TGI with each of the two gas mixtures (Figure 3). Compared with the nitrogen-oxygen mixture, the helium-oxygen mixture reduced $\mathrm{PaCO}_{2}$ by $7.6 \mathrm{mmHg}(\mathrm{p}<0.01)$ and improved $\mathrm{PaO}_{2}$ by $14 \mathrm{mmHg}(\mathrm{p}<0.01)$. AMP during TGI was significantly lower with the helium-oxygen mixture than with the nitrogen-oxygen mixture $(\mathrm{p}<0.01)$ and did not significantly impact MAP (Table 2).

\section{Discussion}

Helium may alter gas exchange during HFOV via a number of mechanisms. Because helium is less dense than nitrogen, the frictional forces in turbulent flows are reduced with helium as compared to oxygen-enriched air. For a given set of airway dimensions, turbulent flow results in a higher resistance than laminar flow. In addition, mechanical ventilation through a narrow ETT and airway, particularly in pediatric and neonatal patients, may further increase the Reynolds number, thus resulting in greater turbulent flow $[15,16]$. With helium, the calculated Reynolds number is lower $(<200)$, which may change regions of turbulent flow to laminar flow, reducing resistance and energy leakage. As resistive forces and

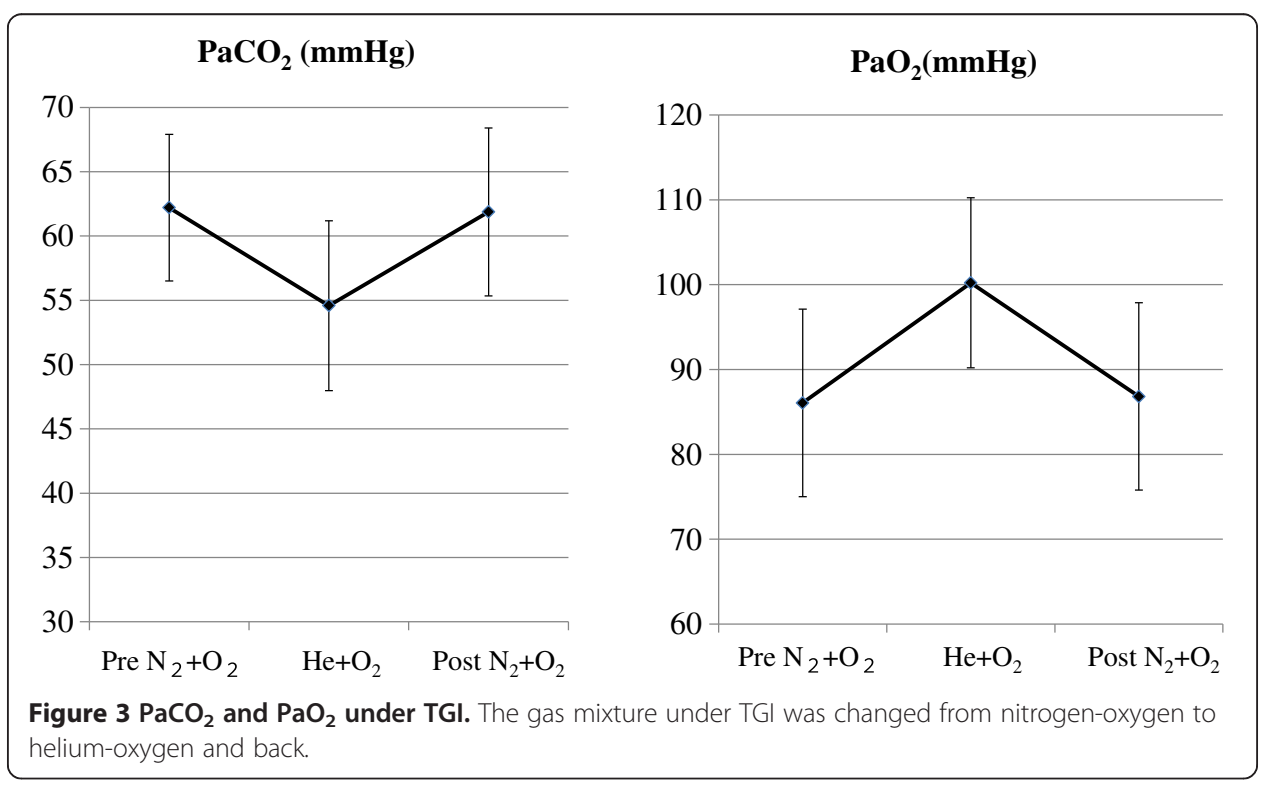


Table 2 AMP and MAP change during the animal experiment

\begin{tabular}{|c|c|c|c|c|c|c|c|c|c|}
\hline & No TGI & $\mathrm{TGI} \mathrm{N}_{2}+\mathrm{O}_{2}$ & $\mathrm{TGI} \mathrm{He}+\mathrm{O}_{2}$ & TGI $\mathrm{N}_{2}+\mathrm{O}_{2}$ & $\mathrm{TGI} \mathrm{He}+\mathrm{O}_{2}$ & TGI $\mathrm{N}_{2}+\mathrm{O}_{2}$ & $\mathrm{TGI} \mathrm{He}+\mathrm{O}_{2}$ & TGI $\mathrm{N}_{2}+\mathrm{O}_{2}$ & No TGI \\
\hline Rabbit $1 \mathrm{AMP}\left(\mathrm{cm} \mathrm{H}_{2} \mathrm{O}\right)$ & 19 & 19.2 & $17.4^{*}$ & 19.5 & $17.7^{*}$ & 19.3 & $17.2^{*}$ & 19.2 & 19.8 \\
\hline Rabbit 2 AMP $\left(\mathrm{cm} \mathrm{H}_{2} \mathrm{O}\right)$ & 17.5 & 17.5 & $15.9^{*}$ & 17.5 & $16.1^{*}$ & 17.9 & $16^{*}$ & 17.6 & 17.8 \\
\hline Rabbit 3 AMP $\left(\mathrm{cm} \mathrm{H}_{2} \mathrm{O}\right)$ & 15.8 & 15.9 & $14.2^{*}$ & 16 & $14.4^{*}$ & 16 & $14.4^{*}$ & 16.1 & 16.3 \\
\hline Rabbit I MAP $\left(\mathrm{cm} \mathrm{H}_{2} \mathrm{O}\right)$ & 12 & 11.9 & 11.7 & 12 & 11.6 & 11.8 & 11.6 & 11.8 & 12 \\
\hline Rabbit 2 MAP $\left(\mathrm{cm} \mathrm{H}_{2} \mathrm{O}\right)$ & 12 & 12 & 12.1 & 12.2 & 12.1 & 12.2 & 12 & 12.1 & 12.1 \\
\hline Rabbit 3 MAP $\left(\mathrm{cm} \mathrm{H}_{2} \mathrm{O}\right)$ & 12.7 & 12.7 & 12.7 & 12.9 & 12.7 & 12.9 & 12.8 & 12.7 & 12.8 \\
\hline
\end{tabular}

AMP amplitude, MAP mean air-way pressure, $T G$ t tracheal gas insufflation.

*: $\mathrm{p}<0.01$. 
energy dissipation are decreased, tidal volume per oscillation increases. This theory has been confirmed before in a laboratory study [8]. In theory, because of its lower density, helium may favorably alter gas exchange through the pendelluft effect, inhalation/exhalation flow asymmetry, Taylor dispersion, and molecular diffusion [9].

By flushing dead space, continuous TGI may allow reductions in respiratory support. The effect of continuous TGI is based mainly on the replacement of end-tidal gas in the instrumental dead space with an inspiratory gas mixture. Continuous TGI allows the use of low-volume ventilation over a prolonged period and reduces the duration of mechanical ventilation in preterm infants [17]. To facilitate $\mathrm{CO}_{2}$ transport without increasing SV and AMP, a helium-oxygen mixture was administered to the turbulent zone using TGI techniques.

When using a helium-oxygen mixture for TGI, $\mathrm{CO}_{2}$ excretion speed increases under constant SV. This effect is attributed to the nature of helium in the turbulent zone. A significant decrease in $\mathrm{PaCO}_{2}$ was shown in animal experiments performed to reproduce the effects apparent in the bench test. The concentration of helium in the test lung that resulted from mixing the TGI flow with the main flow was same as main flow. When we supplied $0.6 \mathrm{ml} / \mathrm{min}$ of TGI flow, helium-oxygen was not needed on the ventilator. We therefore propose that TGI offers a very simple, cost-effective means of supplying helium-oxygen during HFOV, without the need to adapt/calibrate the ventilator for the use with helium-oxygen and avoiding the high gas consumption associated with a high bias flow rate.

One limitation of the present study was that our experiment was performed in normal animal lungs. The low density of helium does not always reduce resistance [18]. Different types and phenotypes of obstructive airway disease manifest in different regions of the lung. The effectiveness of TGI on helium-oxygen mixture HFOV may thus differ according to the type of obstructive airway disease. Further research using lung injury models is therefore warranted.

\section{Conclusion}

This study demonstrated that a helium-oxygen mixture delivered into the trachea using a tracheal gas insufflation (TGI) technique enhances $\mathrm{CO}_{2}$ elimination and offers a simple cost-effective means of achieving helium-oxygen mixture HFOV.

Competing interests

The authors declare that they have no competing interests.

\section{Authors' contributions}

$A B$ participated in the design of the study and performed the statistical analysis. TN conceived of the study, participated in its design and coordination and helped to draft the manuscript. TA participated in the design of the study and performed the statistical analysis. KK participated in the design of the study and performed the statistical analysis. All authors have read and approved the final manuscript.

\section{Acknowledgements}

This study was funded by a grant for scientific research from the Ministry of Health and Welfare of Japan, and Air Water R\&D Co., Ltd.

${ }^{1}$ Department of Pediatrics, Shinshu University School of Medicine, Matsumoto, Nagano 390-8621, Japan. ${ }^{2}$ Division of Neonatology, Nagano Children's Hospital, Toyoshina, Azumino City, Nagano 399-8288, Japan. ${ }^{3}$ First Development Group, Corporate Research Division, Air Water R\&D Co., Ltd, Matsumoto, Nagano 390-1701, Japan. 
References

1. Bohn DJ, Miyasaka K, Marchak BE, Thompson WK, Froese AB, Bryan AC: Ventilation by high-frequency oscillation. J Appl Physiol 1980, 48:710-716.

2. Slutsky AS: Mechanisms affecting gas transport during high frequency oscillations. Crit Care Med 1984, 12:713-717.

3. Courtney SE, Durand DJ, Asselin JM, Hudak ML, Aschner JL, Shoemaker CT, Neonatal Ventilation Study Group: High-frequency oscillatory ventilation versus conventional mechanical ventilation for very-low-birth-weight infants. N Engl J Med 2002, 347:643-652.

4. Johnson AH, Peacock JL, Greenough A, Marlow N, Limb ES, Marston L, Calvert SA, United Kingdom Oscillation Study Group: High-frequency oscillatory ventilation for the prevention of chronic lung disease of prematurity. N Engl J Med 2002, 347:633-642.

5. Marlow N, Greenough A, Peacock JL, Marston L, Limb ES, Johnson AH, Calvert SA: Randomised trial of high frequency oscillatory ventilation or conventional ventilation in babies of gestational age 28 weeks or less: respiratory and neurological outcomes at 2 years. Arch Dis Child Fetal Neonatal Ed 2006, 91:F320-F326.

6. Chang HK: Mechanisms of gas transport during ventilation by high-frequency oscillation. J Appl Physiol 1984, 56:553-563.

7. Katz I, Caillibotte G, Martin AR, Arpentinier P: Property value estimation for inhaled therapeutic binary gas mixtures: $\mathrm{He}, \mathrm{Xe}, \mathrm{N}_{2} \mathrm{O}$, and $\mathrm{N}_{2}$ with $\mathrm{O}_{2}$. Med Gas Res 2011, 1:28.

8. Jaeger MJ: High-frequency ventilation in dogs with three gases of different densities. J Appl Physiol 1991, 70:2188-2192.

9. Katz A, Gentile MA, Craig DM, Quick G, Meliones JN, Cheifetz IM: Heliox improves gas exchange during highfrequency ventilation in a pediatric model of acute lung injury. Am J Respir Crit Care Med 2001, 164:260-264

10. Katz A, Gentile MA, Craig DM, Quick G, Meliones JN, Cheifetz IM: Heliox does not affect gas exchange during high-frequency oscillatory ventilation if tidal volume is held constant. Crit Care Med 2003, 31:2006-2009.

11. Stucki P, Scalfaro P, de Halleux Q, Vermeulen F, Rappaz I, Cotting J: Successful management of severe respiratory failure combining heliox with noninvasive high-frequency percussive ventilation. Crit Care Med 2002, 30:692-694.

12. Winters JW, Willing MA, Sanfilippo D: Heliox improves ventilation during high-frequency oscillatory ventilation in pediatric patients. Pediatr Crit Care Med 2000, 1:33-37.

13. Zeynalov B, Hiroma T, Nakamura T: Effects of heliox as carrier gas on ventilation and oxygenation in an animal model of piston-type HFOV: a crossover experimental study. BioMedical Engineering OnLine 2010, 9:71.

14. Kalous $P$, Kokstein Z: Instrumental dead space in neonatology, and its elimination by continuous tracheal gas insufflation during conventional ventilation. Acta Paediatr 2003, 92:518-524.

15. Gainnier M, Forel JM: Clinical review: Use of helium-oxygen in critically ill patients. Crit Care 2006, 10:24.

16. Orsini AJ, Stefano JL, Leef KH, Jasani M, Ginn A, Tice L, Nadkarni VM: Heliox improves pulmonary mechanics in a pediatric porcine model of induced severe bronchospasm and independent lung mechanical ventilation. Crit Care 1999, 3:65-70.

17. Dassieu G, Brochard L, Benani M, Avenei S, Danan C: Continuous tracheal gas insufflation in preterm infants with hyaline membrane disease. A prospective randomized trial. Am J Respir Crit Care Med 2000, 162:826-831.

18. Martin AR, Katz IM, Jenofi K, Caillibotte G, Brochard L, Texereau J: Bench experiments comparing simulated inspiratory effort when breathing helium-oxygen mixtures to that during positive pressure support with air. BMC Pulm Med 2012, 12:62.

doi:10.1186/1475-925X-12-29

Cite this article as: Baba et al:: Extremely low flow tracheal gas insufflation of helium-oxygen mixture improves gas exchange in a rabbit model of piston-type high-frequency oscillatory ventilation. BioMedical Engineering OnLine 2013 12:29.

\section{Submit your next manuscript to BioMed Central and take full advantage of:}

- Convenient online submission

- Thorough peer review

- No space constraints or color figure charges

- Immediate publication on acceptance

- Inclusion in PubMed, CAS, Scopus and Google Scholar

- Research which is freely available for redistribution

Submit your manuscript at www.biomedcentral.com/submit 